\title{
NEW INSULATING FLUIDS AND DIAGNOSTIC TECHNIQUES FOR PAPER-OIL INSULATED EQUIPMENT ${ }^{1}$
}

\author{
M. N. Lyutikova, ${ }^{2}$ A. A. Konovalov, ${ }^{3}$ and S. M. Korobeinikov ${ }^{4}$
}

Translated from Élektricheskie Stantsii, No. 11, November 2020, pp. 35 - 42.

\begin{abstract}
In 2021, the International Council on Large Electric Systems (CIGRE) will celebrate its centenary. CIGRE Sessions are traditionally held face-to-face in Paris once every even-numbered year. However, in 2020, in response to the coronavirus pandemic, the organizers of the 48th CIGRE Session decided to hold a virtual meeting for experts, specialists, engineers, and researchers from all over the world. The result was an e-session that included engaging seminars, tutorials, and discussions. At the virtual meeting, participants discussed various problems and challenges currently affecting all areas of the energy sector. Current pressing issues include the development of informative diagnostic techniques for oil-filled equipment, as well as the potential applicability of environmentally friendly biodegradable synthetic and natural esters for use as liquid insulation in high-voltage equipment. This review presents the latest research, practical solutions and reports on the experience of applying new techniques and novel liquid insulating materials. Valuable and up-to-date information in these fields is provided by experts and specialists from all over the world.
\end{abstract}

Keywords: 48th CIGRE session; liquid dielectrics; esters; diagnostic technique for high-voltage equipment.

Formed in 1921 (Paris, France), the International Council on Large Electric Systems (CIGRE) comprises a global community dedicated to collaborative development and sharing of best practices in power system design and management. CIGRE aims to facilitate interaction and knowledge exchange between specialists and experts in all aspects of electric power systems. The community unites thousands of professionals from over 90 countries and 1250 member organizations, including some of the world's leading experts. CIGRE has 59 National Committees offering various technical perspectives and experience-sharing between experts from across the globe within 16 key power system domains (see Table 1).

Every two years, CIGRE organizes meetings for specialists at different levels in Paris, where they spend several days discussing topical issues, finding effective solutions to energy sector issues, as well as fostering new collaborations. In general, the key results of these meetings include reliability of power supply and ensuring constant professional development in this area. Although the biannual meeting of power engineers was to have been held in Paris in August 2020, this

\footnotetext{
1 The paper is based on the materials of the CIGRE e-session 2020.

2 Yamal-Nenets Main Power Grid Company, FGC UES branch, Noyabrsk, Yamal-Nenets Autonomous Area, Russia, e-mail: m.lyutikova@mail.ru

${ }^{3}$ Federal Grid Company of Unified Energy System (FGC UES), Moscow, Russia.

${ }^{4}$ Novosibirsk State Technical University, Novosibirsk, Russia.
}

plan could not be implemented under pandemic conditions. Nevertheless, in response to the new circumstances, online sessions were organized for all delegates who wanted to share their knowledge, achievements, and experience.

From August 24 to September 3, 2020, specialists, engineers, and experts from all over the world discussed numerous interesting and topical issues covering all areas of power system design and management by means of special online platforms. Participants in the CIGRE e-session discussed over 800 presented papers (see Fig. 1), including those pertaining to the D1 domain (Materials and Emerging Test Techniques). The development of more informative diagnostic techniques, as well as their practical application for the technical evaluation of high-voltage electrical equipment, is of primary importance for reliable power supply. An equally relevant issue is the use of natural and synthetic esters as media for liquid dielectrics, which represent more environmentally friendly biodegradable fluids as compared to mineral oil.

In paper A2-301, entitled "Ten Years of Experience with Natural Ester in $245 \mathrm{kV}$ : Shunt Reactor of Vilhena Substation," its Brazilian authors share their experience of operating a shunt reactor with natural ester used as the insulating fluid (R. I. Da Silva, I. P. Arantes, I. Capinos, L. De Oliveira, M. A. De Lima, and G. L. Nicola). Although this reactor was originally designed to employ ordinary mineral oil as a liquid 
dielectric, natural esters were substituted without changing any of the reactor's design features. A three-phase 22 MVAr, $245 \mathrm{kV}$ reactor filled with ester was operated for ten years with periodic monitoring of physicochemical parameters.

The authors note the following changes in the characteristics of the natural ester used: a slight increase in the acid number over the last two years of operation, a significant rise in moisture content but with no reduction in dielectric strength, and a rise in the dissipation factor from 10.85 to $38.6 \%$ at $100^{\circ} \mathrm{C}$ with nearly unchanged viscosity (at $40^{\circ} \mathrm{C}$ ). The concentration of combustible gases $\left(\mathrm{H}_{2}, \mathrm{CH}_{4}, \mathrm{C}_{2} \mathrm{H}_{2}\right.$, $\mathrm{C}_{2} \mathrm{H}_{4}, \mathrm{C}_{2} \mathrm{H}_{6}$ ), as well as both $\mathrm{CO}$ and $\mathrm{CO}_{2}$, remained below the maximum allowable value throughout the entire operation. A gradual increase in ethane, $\mathrm{CO}$ and $\mathrm{CO}_{2}$ was observed, along with a sharp increase in the hydrogen concentration during specific periods of reactor operation. In general, the authors report a positive experience of using natural ester as an insulating fluid in a reactor located in a humid climate.

Synthetic and natural esters are known to have a slightly higher viscosity than mineral oil, especially at low temperatures. This factor limits the use of ester-based fluids as insulation for power transformers. For example, paper D1-204 "Investigation into the Effect of Cold Temperature on the Physical Properties of Dielectric Liquids" presents the results of measuring viscosity and other parameters of synthetic and natural rapeseed esters when cooling fluids from $+25^{\circ} \mathrm{C}$ to $-30^{\circ} \mathrm{C}$ (P. M. Livesey and J. Malde). The reported data are of particular interest for understanding the risks associated with putting a transformer under load following long downtime periods during the cold season when the ambient temperature can drop to $-30^{\circ} \mathrm{C}$ or below. After exposing rapeseed oil to a temperature of $-20^{\circ} \mathrm{C}$ for $168 \mathrm{~h}$, the authors observed a slight increase in its viscosity along with the

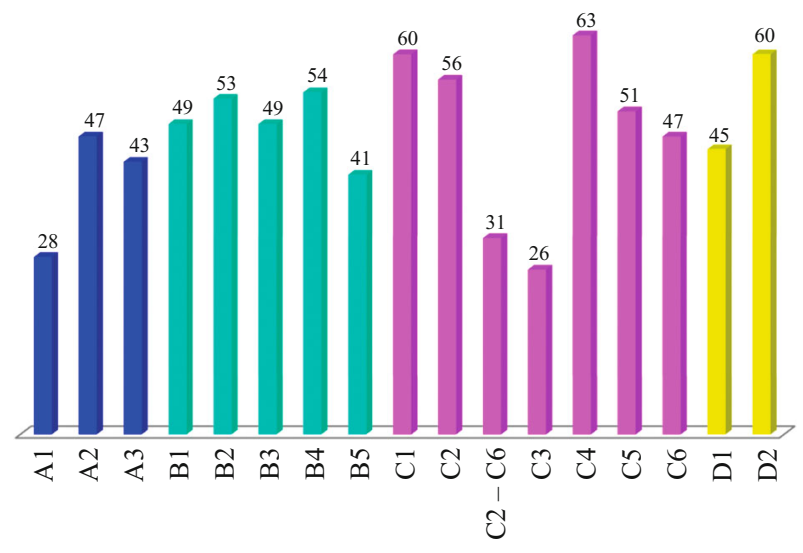

Fig. 1. Number of papers presented at CIGRE e-session 2020 by study committee domains.

formation of solid particles, contributing to the clogging of oil-flow channels in the active part of the transformer, cooling system elements, etc. In general, since the emergence of solid inclusions in rapeseed oils at subzero temperatures affects the operation of oil pumps included in the cooling system for forced-start conditions, this effect must be considered when performing a cold start of transformers having the following cooling system types: Oil Forced Air Forced (OFAF) and Oil Forced Water Forced (OFWF). In general, starting conditions are likely to be similar to the preheating requirements for oil-immersed transformers having OFAF and OFWF systems that are given in the grid code. Unlike rapeseed oil, the synthetic ester exhibited no significant increase in viscosity when cooled to $-40^{\circ} \mathrm{C}$. In addition, no formation of ice or solid matter was observed even following prolonged exposure to low temperatures.

TABLE 1. CIGRE's Study Committees and Domains of Work

\begin{tabular}{|c|c|c|}
\hline Committee & Domain of work & Scope \\
\hline A1 & Rotating Electrical Machines & Turbine generators, hydro-generators, non-conventional machines, and large motors \\
\hline $\mathrm{A} 2$ & Power Transformers and Reactors & $\begin{array}{l}\text { Design, production, and operation of all types of transformers, their components, and } \\
\text { regulators }\end{array}$ \\
\hline A3 & Transmission and Distribution Equipment & Devices for switching, interrupting, or limiting currents, capacitors, etc. \\
\hline B1 & Insulated Cables & AC and DC insulated power cable systems for on-land and submarine applications. \\
\hline B2 & Overhead Lines & Overhead power lines and their components (conductors, supports, foundations, etc.) \\
\hline B3 & Substations and Electrical Installations & $\begin{array}{l}\text { Construction, operation, and management of substations and electrical installations, ex- } \\
\text { cluding generators }\end{array}$ \\
\hline B4 & DC Systems and Power Electronics & HVDC links, power electronics, etc. \\
\hline B5 & Protection and Automation & $\begin{array}{l}\text { Design, application, and management of power system protection, technical means, } \\
\text { phasor measurement technologies, etc. }\end{array}$ \\
\hline $\mathrm{C} 1$ & Power System Development and Economics & Economic indicators, systems analysis method, asset management strategies \\
\hline $\mathrm{C} 2$ & Power System Operation and Control & Aspects of managing technical and other resources in power system operation \\
\hline $\mathrm{C} 3$ & Power System Environmental Performance & Determining and assessing the environmental impact of power systems \\
\hline $\mathrm{C} 4$ & Power System Technical Performance & Methods and tools for analyzing technical performance, reliability assessment \\
\hline $\mathrm{C} 5$ & Electricity Markets and Regulation & Analysis of approaches to the organization of energy supply, market structure, etc. \\
\hline C6 & $\begin{array}{l}\text { Active Distribution Systems and Distributed } \\
\text { Energy Resources }\end{array}$ & $\begin{array}{l}\text { Implementation of distributed generation, assessment of influence and technical require- } \\
\text { ments, etc. }\end{array}$ \\
\hline D1 & Materials and Emerging Test Techniques & Materials for electrical equipment, diagnostic techniques, etc. \\
\hline D2 & Information Systems and Telecommunication & Emerging technologies, standardization principles, technical performance, etc. \\
\hline
\end{tabular}


In paper A2-304, the authors consider the behavior of esters during a cold start of a 400 MVA $420 \mathrm{kV}$ power transformer ("Power Transformers Using Esters Next Generation - Ready to Cope with all Grid Operation Challenges"; R. Fritsche, F. Trautmann, S. Wittemann, J. Christian, G. Adamietz, and D. Wenger). On the basis of data available from laboratory tests along with empirical information gained through operation of first-generation natural-ester-filled transformers ( $300 \mathrm{MVA}, 420 \mathrm{kV}$ ), the design of the transformer was modified to enable a reduction in its overall dimensions. One advantage of the new (second-generation) transformer consists in its ability to be put into operation at low ambient and fluid temperatures $\left(-25^{\circ} \mathrm{C}\right)$, helping to overcome operational limitations associated with the use of ester fluids during the cold season. However, the authors note that on-load tap changers (OLTCs) filled with ester fluids are still not suitable for operation at temperatures below $-12^{\circ} \mathrm{C}$.

The operation of OLTCs filled with ester fluids (natural and synthetic) does not raise any concerns at positive temperatures, as reported in paper A2-306 "Reliability Evaluation of Ester Oil Filled On-Load Tap Changers through Critical Tests" (R. V. Talegaonkar, O. C. Kolambkar, and T. P. Govindan). The authors of the paper monitored the dielectric fluid while testing an OLTC for durability $(50,000$ switching operations at rated current, test procedure in accordance with clause 5.2.3.2 of IEC 60214-1) and recorded parameters prior to, during, and following the OLTC switching operations. The applied current and voltage oscillograms were recorded starting from 0 to 50,000 operations. Prior to pouring the fluid into the OLTC and at given intervals, the following parameters were determined: color, breakdown voltage, surface tension, mechanical impurities, and concentration of dissolved gases. In addition, the results of studying the corresponding ester were recorded using Fourier-transform infrared spectroscopy (FTIR spectroscopy) both prior to and following the test. On the basis of the obtained results, the experts confirmed the possibility of using ester for insulation in OLTCs.

The paper also notes a low combustible gas content in ester fluids (as compared to mineral oil); such gases are generally formed as a result of arc formation during switching in OLTCs. Electron microscopy revealed a lower rate of contact erosion of an OLTC filled with esterised oil as compared to the contacts of a mineral-oil-filled OLTC. The latter fact also suggests the positive experience of using ester as a liquid dielectric.

Another relevant issue is a reduction in the dielectric strength of insulating fluid due to the transfer of moisture from the insulation of transformer windings resulting from their intense heating, especially in the case of repeated shortterm overloads (not exceeding $30 \mathrm{~min}$ ), with a subsequent decrease in the load and consequent temperature of the transformer and insulating fluid. This is explained in terms of the diffusion of water from cellulose into oil by heated windings.
Once the load is reduced, water molecules diffuse from the oil toward the solid insulation. However, these two processes run at different rates. Thus, in paper D1-108 "Evaluation of Dynamic Loading Capability for Optimal Loading Strategies of Power Transformers," the authors report results of simulating water migration between insulating materials (oil-cellulose) in transformers filled with mineral oil and natural ester under varying load conditions (I. Lupandina, W. Gawlik., M. Schrammel, A. Ilgevicius, M. Kurten, and K. Viereck). Here, the simulations were carried out and evaluated in Matlab ${ }^{\circledR}$ Simulink $^{\circledR}$.

The simulation results indicate that an additional overload (with a multiplicity of 1.5 for $30 \mathrm{~min}$ ) of the transformer $4 \mathrm{~h}$ after the first operating period characterized by a similar overload level leads to an unacceptable increase in the moisture content in the lower oil layers of the transformer's main tank. The period following the second overload poses a serious problem, particularly when using mineral oil, whose water solubility is much lower than that of ester. Under actual operating conditions, a similar situation can present a high risk of insulation failure. This effect is additionally exacerbated by low ambient temperatures and a high water content in the transformer. However, the relative moisture saturation of natural ester remains within acceptable limits due to the solubility of water in natural ester being much higher than that of water in mineral oil.

Paper A2-305 presents some promising results of testing mineral oils and ester-based liquid dielectrics for their compatibility with the structural materials of high-voltage equipment ("Compatibility Tests between Solid and Liquid Materials for Reliable Transformers"; C. Perrier, M.-L. Coulibaly, and M. Marugan). The main signs indicating incompatibility between dielectric fluid and equipment materials are visually-detected physical changes (color, hardness, swelling, shrinkage, etc.). This incompatibility is quantitatively reflected in a rapid deterioration of the electrical insulating properties of dielectric liquids.

The authors of this paper also describe tests for the compatibility of basic structural materials (cellulose paper, cardboard, varnish, coated and uncoated steel, and rubber gaskets) with liquid dielectrics, including natural ester. The specialists conclude that all relevant materials are compatible with both natural ester and mineral oil based on the tested values of the surface tension, acid number, dielectric loss tangent, and measured resistivity of dielectric fluids. A specific type of rubber gaskets proved to be an exception to this list of materials since the authors observed marked swelling of rubber samples and darkening of fluids following three months of their exposure to oil and ester.

Paper D1-302, entitled "Replacement of Area Substation Transformers with Flexible Units of Reduced Footprint and Increased Overloadability" (R. Szewczyk, J.-C. Duart, A. O. Malley, K. Kaineder, and E. Schweiger), presents positive results of studying the compatibility of synthetic (Midel 
7131) and natural (Midel eN 1215 and Midel eN 1204) esters with insulation parts and winding insulation from aramid:

- Nomex 910 insulation paper (cellulose electrotechnical paper reinforced with aramid components);

- Nomex 410 insulation paper (aramid insulation).

In the paper "Large Power Autotransformers Filled with Natural Ester - Working Parameters from the Field and Maintenance Notes," Italian specialists describe their valuable experience of operating a transformer filled with Cargill's Envirotemp FR3 natural ester fluid (S. Sacco, F. Scatiggo, C. Serafino, F. M. Pepe, L. Lombini, F. Ferrari, and D. Rogora). As compared to mineral oil, the Envirotemp FR3 natural ester has the following advantages: high fire point, nontoxicity, high biodegradability, and low costs incurred as a result of leaks. However, given the limited experience of using natural esters as dielectric fluid for power equipment as compared to commonly used mineral oil, careful monitoring of the relevant parameters is required.

The authors note that autotransformer monitoring systems combined with measuring instruments at the substations of operating organizations allow the following parameters to be measured: temperature of the insulating fluid (ester); winding temperature; concentration of gases dissolved in natural ester; water content; on-load tap changer (OLTC) position; permittivity and conductance of the fluid; online measurement of partial discharges; load currents in transformer windings; levels and nature of the load; shortcircuit currents flowing in the adjacent grid and through the transformer. The accumulation of a dataset of the specified quantities allows some estimates to be made as to the technical condition of equipment after a period of about a year and a half following the onset of their regular recording.

In addition, the report contains the measurements of some parameters. Specifically, following $16,000 \mathrm{~h}$ of transformer operation, the concentration of gases dissolved in ester, as well as its water content, remain at the initial level (measured following $144 \mathrm{~h}$ of transformer operation). An additional positive result consists in a decrease in the solid insulation moisture level from 3.9 to $3.4 \%$ as revealed by the Polarization and Depolarization Current test (PDC) carried out after one year of operation. This result confirms the positive moisture-retaining characteristic of ester, which helps to protect solid insulation from excessive moisturization.

Studies conducted by Italian specialists and presented in the paper "LCA and Smoke Test of Dielectric Fluids based on Natural Esters" also support the use of natural esters as insulating and cooling media in power transformers (F. Scatiggio, E. Breda, L. Calcara, G. Campi, L. Parodi, R. Pedriali, and M. Pompili). The combustion of ester, which in practice can occur during a fire caused by transformer damage, releases far fewer harmful substances (nitrogen oxides, carbon oxides, particulate organic carbon, polycyclic aromatic hydrocarbons, volatile organic compounds, and aldehydes) into the atmosphere as compared to the combustion of the same volume of mineral oil. Moreover, the use of vegetable oil in transformers enables a reduction in greenhouse gas emissions by $50 \%$, positively affecting the environment and human health.

No less interesting was a report by specialists from Hydro-Québec (Canada), one of the largest energy companies in the world. In paper A2-303, the authors cite actual cases of transformer fault detection and recommendations for timely maintenance aimed at preventing serious defects ("Continuous Improvement of Transformer Specifications at a Large Utility," C. Rajotte and S. Proulx). Such timely and appropriate measures significantly extend the equipment life cycle.

The basis for developing and implementing measures required to ensure the reliable long-term operation of highvoltage equipment includes test results obtained using various diagnostic techniques. The more informative a technique is, the higher the probability that a fault developing in the insulation of a high-voltage transformer will be detected early. It is for this reason that diagnostic techniques are constantly being developed and improved. When using less studied insulating materials, such as synthetic and natural esters, it is important to employ highly sensitive test methods.

Evaluating the oxidative stability of ester fluids is of primary importance in understanding the possible use of natural and synthetic esters for insulation in high-voltage equipment. The paper "Proposal of Test Method for Evaluating the Induction Time (IT) of Natural Ester Insulating Oils" presents a test method for evaluating the induction time of esters as a measure of oxidative stability (A. C. P. Martins, L. Chaves, and $\mathrm{H}$. Wilhelm). In their experiments, the authors used four commercially available natural esters (natural ester insulating fluids): three polyunsaturated esters having a low oleic acid content and one monounsaturated ester having a high oleic acid content.

The accelerated aging of esters was performed under conditions described in EN 14112, IEC 61125, and ASTM D2440. After increasing the test duration, the following physicochemical parameters of the samples were determined at specific intervals: soluble acids, volatile acids, conductance, and viscosity. The study results yielded several important conclusions regarding the effectiveness of using these standards to evaluate the oxidative stability of ester fluids. Firstly, despite their various chemical compositions, IEC 61125 does not provide a basis for distinguishing between the induction times of all four esters. This fact is attributable to the accelerated oxidation conditions specified in IEC 61125 not being as strictly defined as those outlined in EN 14112 and ASTM D2440. Secondly, the authors were able to rank the natural esters by induction time or oxidative stability using the ASTM D2440 method (NIE $4>$ NIE $3>$ NIE 2 $>$ NIE 1). In this series, the first ester possesses lower oxidative capacity. Due to the accelerated oxidation conditions detailed in EN 14112 (oxygen flow rate of 10 liters/h) being used to distinguish between the induction times of polyunsat- 
urated and monounsaturated NIEs, this method is recommended for the simple, automated, and rapid determination of NIEs of unknown origin, as well as requiring only a small sample amount.

Although the oxidative stability of insulating fluids is usually measured for newly developed dielectrics, an equally significant aspect involves understanding the condition of insulation at different operating periods. Recently, the emphasis has been placed on spectral methods giving a better indication of the state of both liquid and solid insulation elements.

Thus, paper D1-103, titled "Identification and Improved Quantification of Inhibitors in Mineral Insulating Oils using FTIR Spectroscopy and Partial Least Squares Regression," proposes an improved procedure for identifying additives in oil using FTIR spectroscopy based on a partial least squares regression (PLSR) model (P. Agren, T. Lillhonga, and L. Melzer). The practical novelty of the PLSR model as compared to the traditional FTIR method consists in the possibility of separately determining the mass concentrations of 2,6di-tret-butyl-4-methylphenol (DBPC or ionol), 2,6-di-tretbutylphenol (DBP), as well as identifying the decomposition product of ionol - 2,6-di-tert-butyl-p-benzoquinone (DBQ).

A procedure presented in the report "Spectral Measurement of the Precipitations Composition in OIP Insulation of the High-Voltage Bushings" ascertained the composition of impurities in precipitates and wax deposits on solid insulation sampled during the disassembly of high-voltage bushings (S. Korobeynikov, M. Lyutikova, and A. Konovalov). The authors concluded that the main precipitate components included the well-studied sulfide $\mathrm{Cu}_{2} \mathrm{~S}$, as well as sulfides of other metals ( $\mathrm{PbS}, \mathrm{NiS}, \mathrm{FeS}, \mathrm{ZnS}, \mathrm{Cr}_{2} \mathrm{~S}_{3}, \mathrm{CdS}, \mathrm{CoS}$, and $\mathrm{MnS}$ ), which were identified using a highly sensitive atomic absorption method.

It is crucial to perform timely oil reclamation before a significant amount of undesirable hazardous compounds formed through the oxidation of liquid dielectric components become sorbed into solid insulation elements. Such compounds are known to significantly accelerate the degradation of solid cellulose insulation and adversely affect the mechanical strength of cellulose. Thus, the authors of the paper D1-120 "Oxidative Degradation of Mineral Oils in Power Transformers Over Service Time. Effect of the Economic Owner on Maintenance Strategies" propose a procedure for ranking the state of insulating oil by its acid number as a means of preventing irreversible aging of solid insulation (A. Zaya-Jimenez and L. Arbelaez-Orozco). This procedure allows the signs of early oxidation to be detected to inform preventive measures that can increase the useful life of power transformers and optimize maintenance costs.

Paper D1-210, entitled "Analysis of Stray Gas According to Oil Characteristics and Vacuum Process Conditions of Insulation Oil in Power Transformer," discusses oil decomposition resulting in the formation of gases unrelated to elec- trical or thermal transformer faults (J. H. Song, K. H Lee., J. T. Kim, J. W Lee., and D. H Kim). So-called extraneous gases (hydrogen $\mathrm{H}_{2}$, methane $\mathrm{CH}_{4}$, ethane $\mathrm{C}_{2} \mathrm{H}_{6}$, carbon dioxide $\mathrm{CO}_{2}$, and carbon monoxide $\mathrm{CO}$ ) can be produced via a chemical reaction or oxidation of oil at normal operating temperatures below $140^{\circ} \mathrm{C}$. The authors of the report reach this conclusion on the basis of experimentally confirmed data. Thus, the heating of paraffin and naphthenic oils with steel, copper conductor, and insulating paper to $95^{\circ} \mathrm{C}$ for $164 \mathrm{~h}$ was found to increase the concentration of all gases as compared to the measured concentration of gases in oils with no added materials. The amount of produced gases in the paraffin oil was much higher than in naphthenic oil.

Paper D1-118 "Field Experience in Oil-filled Power Transformers Fault Diagnosis by Frequency Response of Stray Losses (FRSL)" by P. Singkhawat discusses the frequency response of stray losses (FRSL) method. When the concentration of key gases indicates a defect such as overheating or spark formation, FRSL can be combined with dissolved gas analysis (DGA). Overheating or spark formation can occur due to a short circuit in two or more parallel winding conductors or when the connection of the magnetic core sheets results in increased eddy current losses. Transformer faults associated with an increase in eddy current losses are generally detected at higher frequencies. The FRSL method can be used to detect faults that cannot always be identified using other methods.

In this connection, the specialist authors cite two case studies involving the use of the FRSL method to detect transformer faults. The former relates to a single-phase 333.3-MV · A 525-kV autotransformer (phase C), which functioned properly for five years. However, a routine chromatographic analysis of dissolved gases performed in 2016 indicated overheating at a high temperature (high concentration of $\mathrm{C}_{2} \mathrm{H}_{4}$ ) along with arcing processes (high concentration of $\mathrm{C}_{2} \mathrm{H}_{2}$ ). The following standard tests revealed no deviations from the norm: measurements of winding and bushing insulation resistance, short-circuit resistance, winding and bushing capacitance, frequency response analysis (FRA), etc. However, FRSL measurement results obtained at $400 \mathrm{~Hz}$ showed that eddy current losses for phase $C$ were significantly higher than in phases $A$ and $B$, i.e., by about $33 \%$. An inspection carried out after removing the transformer from service revealed a metal pipe piece resting on the magnetic core and connecting several steel plates, which had led to the observed increase in eddy currents and consequent arcing processes.

The latter example featured defect detection in a $50-\mathrm{MV} \cdot \mathrm{A} 115-\mathrm{kV}$ three-phase transformer that had functioned properly for 28 years. Although routine high-voltage tests revealed no deviations from the norm, a DGA of the oil showed an increase in the concentrations of ethane $\mathrm{C}_{2} \mathrm{H}_{6}$ and acetylene $\mathrm{C}_{2} \mathrm{H}_{2}$, indicating overheating at low temperatures and spark formation. The performed FRA indicated winding 
deformation, while other tests (determination of transformer ratio, excitation current, winding resistance) that could confirm a short circuit in the windings revealed no deviations from the standard values. However, the FRSL data obtained at $400 \mathrm{~Hz}$ indicated that stray losses were by $17 \%$ higher in the contact between high-voltage (HV) and low-voltage (LV) windings than in the other two phases. The internal inspection revealed a radial bending of phase $C$, as well as signs of overheating or spark formation in the windings. Thus, the authors of this paper (D1-118) emphasize that it would have been impossible to detect any signs of short circuit in the windings without the FRSL and DGA test results.

Paper D1-114, entitled "On-Line Diagnosis Methods for Transformer Winding Deformation Based on Running Voltage and Current Correlation Mining," describes an intelligent interactive technique for the deformation diagnostics of windings in transformers (Y. Zheng, W. Wang, H. Yao, C. Li, X. Sun, L. Liu, W. Du, and D. Wen). With the application of a specific automatic algorithm for analyzing signs of faults, the authors performed tests using actual electrical equipment. The study yielded the latent characteristics of winding deformation in 29 transformers, revealed the general pattern for different transformers prior to and following winding deformation, and defined the type of winding deformation fault as the basis for deformation evaluation. Of the 29 transformers, $27(93.10 \%)$ were correctly classified, while 24 samples $(88.89 \%)$ were correctly analyzed in terms of winding deformation faults.

Paper-based insulation materials constitute an essential component of a transformer insulation system. A highly hygroscopic material, cellulose insulation is typically subjected to vacuum drying at a specific temperature to remove moisture. Factory-performed vacuum drying reduces moisture content in insulation from $6-7 \%$ by weight to $0.5-1 \%$ prior to oil impregnation. In order to control the moisture content of solid insulation prior to oil impregnation and during factory drying, the authors of "Monitoring of Active Part Drying for Instrument Transformers by Dielectric Measurements" propose carrying out dielectric measurements in online mode (C. Perrier, Z. Roman, and Y. Kieffel). Dielectric frequency response (DFR) or frequency domain spectroscopy (FDS) comprise excellent approaches for quality monitoring the vacuum drying of paper insulation. In the paper, the authors present case studies describing a positive experience of using these methods to control the drying of solid insulation in online mode.

Paper D1-206, entitled "Characterization of Pressboard Mechanical Properties for Understanding the Dynamic Behavior of Transformer Winding Clamping Pressure," presents a quantitative analysis of mechanical properties exhibited by cardboard insulators and the influence of their condition on clamping pressure in transformer windings (C. Ekanayake, L. Naranpanpanawa, H. Ma, T. K. Saha, G. Russell, and M. Pannu). Increased currents in windings are known to create strong electromagnetic forces during a short circuit, leading to winding deformation and transformer winding displacement. The short-circuit withstand capability (SCWC) is maintained by applying axial pressure to the winding through a clamping system. In order to create necessary axial pressure, a static clamping system is primarily used. While the transformer is in operation, the clamping pressure gradually decreases, resulting in a reduced capability of the transformer to withstand the dynamic influences of flowing short-circuit currents. According to the authors, neither FRA nor any other existing condition assessment technology, such as vibroacoustic methods, can accurately determine the condition of loosened windings.

One of the main reasons for the loss of winding clamping pressure is degradation (aging), resulting in a deterioration of its mechanical properties. During the course of continuous transformer operation, cardboard is subjected to various electrical, mechanical, and thermal loads. A series of laboratory experiments established that the compressibility of pressboard throughout its thickness is highly dependent on moisture, temperature, and aging. As the moisture content of the cardboard and temperature increase, so do the compressibility and thickness of the pressboard parts. Due to aging, cardboard becomes noticeably softer than when new. The authors conclude the necessity to carry out further research on an increased number of considered transformers of different designs.

The existing issue associated with the remaining life of solid cellulose insulation acting as the main component of an oil-cellulose insulation system in an operating transformer remains current. In their paper "Rationalization and High Precision of Transformer Lifetime Evaluation Method," the specialist authors propose a procedure for determining the wear of cellulose insulation (degree of polymerization) based on three-component regression: concentration of furfural, number of cellulose fibers in oil, and temperature analysis (S. Miyazaki, M. Nakai, M. Yoshida, and K. Aoki). Using this comprehensive approach, the authors additionally estimate the residual clamping pressure in transformers that are weakened by the shrinkage of insulating materials.

In the report entitled "A New Method for Evaluating the Degree of Polymerization of Paper Insulation of Power Transformers," Russian scientists propose a new procedure for ascertaining the polymerization of paper insulation using optical spectroscopy to determine reflectance spectra at a wavelength in the range of $650-655 \mathrm{~nm}$ (V. K. Kozlov and A. Kh. Sabitov). A developed and certified device for performing such measurements is described. The advantage of this method is considerable due to quick results, requiring no dangerous reagents, and an obviation of the need to remove paper insulation samples from the highest voltage areas of electrical equipment (since measurements can be performed on site). The procedure and device should be considered as promising in terms of their introduction into an automatic di- 
agnostic system of high-voltage oil-filled substation equipment under active recent development.

In their report D1-115 entitled "Development of a Multi-Parameter Online Monitoring Equipment for EHV Transformer Bushing," engineers present results of testing a developed multi-parameter sensor that can be used for the online monitoring of high-voltage bushings (L. Zhang, Y. Han, S. Wang, J. Wu, A. Guo, and C. Guo). The sensor can measure the $\mathrm{H}_{2}$ content in the range of $0-5000 \mathrm{ppm}$, with an accuracy of $10 \%$, or $15 \mathrm{ppm}$; pressure in the range of $0-1.0 \mathrm{MPa}$ at a resolution of $0.1 \mathrm{kPa}$; as well as temperature in a range varying from $-40^{\circ} \mathrm{C}$ to $+105^{\circ} \mathrm{C}$ at an accuracy of $\pm 1^{\circ} \mathrm{C}$. The response time is under $20 \mathrm{sec}$. The report provides a detailed description of the sensor's design and principle of operation.

As can be seen, the 48th CIGRE session organized in an electronic format allowed all conference participants to share their invaluable experience in all areas of the energy sector, as well as gain valuable knowledge that could subsequently promote more effective cooperation between specialists, engineers, and experts. This synergy is crucial to achieving the primary goal of power engineers from all over the world: reliable and safe power supply. 